\title{
Kajian layanan ekosistem pada sistem agroforestri berbasis kopi di Desa Cisero, Garut
}

\author{
D. A. Hayyun ${ }^{1}$, E. N. Megantara2 ${ }^{2}$, Parikesit $^{2}$ \\ ${ }^{1}$ Bidang Tata Lingkungan, Dinas Lingkungan Hidup Kabupaten Garut, Indonesia \\ 2Pusat Unggulan Lingkungan dan Ilmu Keberlanjutan (PULIK), Universitas Padjadjaran, Bandung, \\ Indonesia
}

\begin{abstract}
Abstrak
Sistem agroforestri melalui pengembangan budi daya kopi menjamin kelangsungan struktur dan proses ekologi di dalamnya. Penelitian ini bertujuan untuk mengetahui jenis dan bentuk layanan ekosistem pada sistem agroforestri berbasis kopi di Desa Cisero, serta mengungkap pengetahuan masyarakat. Penelitian menggunakan metode campuran, yaitu metode kualitatif dan kuantitatif. Hasil penelitian menunjukkan bahwa jenis layanan ekosistem yang tersedia pada sistem agroforestri berbasis kopi di Desa Cisero meliputi jasa penyediaan, pengaturan, pendukung dan kultural. Pengetahuan masyarakat Desa Cisero terhadap layanan ekosistem adalah baik (skor ratarata 74,86$)$. Masyarakat memiliki pengetahuan sangat baik terkait jasa penyediaan (skor rata-rata 91,46), layanan ekosistem dari pohon penaung berupa jasa pengaturan (skor rata-rata 78,66=baik) dan layanan ekosistem dari keberadaan hidupan liar (skor rata-rata 65,65=baik). Adapun faktor yang berpengaruh cukup kuat terhadap peningkatan pengetahuan masyarakat diantaranya luas lahan garapan, lama interaksi dengan tata guna lahan dan sharing pengetahuan dengan keluarga serta kelompok tani (LMDH). Untuk memelihara layanan ekosistem di Desa Cisero, maka strategi yang dapat direkomendasikan meliputi penaatan kebijakan kerjasama budi daya kopi (monitoring, pengawasan, evaluasi dan penegakan hukum), pengaktifan kembali koperasi petani dan fasilitasi bantuan modal, mempertimbangkan pengetahuan ekologi lokal dalam perumusan rencana program dan kegiatan budi daya kopi serta pendokumentasian dan pengorganisasian data yang baik.
\end{abstract}

Kata kunci: layanan ekosistem, pengetahuan masyarakat, sistem agroforestri, kopi

\begin{abstract}
Coffee plantations that were developed through agroforestry ensure continuity of the structure and ecological processes in it. The aim of this research was to determine the type and form of ecosystem services in coffee-based agroforestry systems at Cisero Village and to reveal community based knowledge. The study was conducted by using mixed methods, both of qualitative and quantitative. The study results showed that the type of ecosystem services available in the coffee-based agroforestry systems at Cisero Village were provisioning, regulating, supporting and cultural services. Community based knowledges were relatively high (with an average score of 74.86). The community has a very high knowledge related to the provisioning services (the average score was 91.46), followed by the ecosystem services of the shade trees in the form of regulating services (the average score was $78.66=$ good) and the ecosystem services of the presence of wildlife (the average score $65.65=$ good). The result of statistical test showed a strong correlation between the knowledge about ecosystem services with many factors such as total size of the farm (has), time spent in the area and knowledge and experience exchange with families and farmer groups. In order to maintain ecosystem services in coffee based agroforestry systems in the Cisero Village, there are strategies that can be recommended, such as the compliance of cooperation policy in coffee plantation (monitoring, supervision, evaluation and law enforcement), reactivating the farmer cooperative and financial facilitation, considering the local ecology knowledge in the process of coffee plantation planning and program, proper organization and documentation the coffee data.
\end{abstract}

Keywords: ecosystem services, community based knowledge, agroforestry systems, coffee

\section{PENDAHULUAN}

Pada awalnya, Perum Perhutani yang merupakan Badan Usaha Milik Negara yang bergerak di bidang kehutanan menjalankan model pengelolaan tunggal melalui kebijakannya yang bersifat top down. Suprapto (2014) menyatakan bahwa implementasi model pengelolaan tersebut tidak cukup

\footnotetext{
${ }^{*}$ Korespondensi Penulis

Email : erri311@gmail.com
} 
efektif dalam upaya pencegahan kerusakan dan kemerosotan sumber daya hutan. Hasil penelitian Abdoellah (2012) di DAS Citarum Hulu, sistem budi daya yang dapat menjamin keberlanjutan secara ekonomi dan ekologi untuk mengatasi permasalahan degradasi lingkungan adalah pengelolaan lahan yang melibatkan masyarakat melalui pola kemitraan. Melalui pola tersebut diharapkan masyarakat dapat mengelola sumber daya alam dengan baik.

Pola kemitraan bersama masyarakat diinisiasi oleh Perum Perhutani dengan diterbitkannya SK Dewan Pengawas Perhutani Nomor 136/KPTS/DIR/2001 tentang Pengelolaan Sumberdaya Hutan Bersama Masyarakat atau disingkat PHBM (Hadiyanti 2014; Suprapto 2014). Berdasarkan SK Direksi Perum Perhutani Nomor 268/KPTS/DIR/2007 tentang Pedoman Pengelolaan Sumberdaya Hutan Bersama Masyarakat Plus (PHBM PLUS), PHBM adalah sistem pengelolaan sumber daya hutan dengan pola kolaborasi yang bersinergi antara Perum Perhutani dan masyarakat desa hutan atau para pihak yang berkepentingan dalam upaya mencapai keberlanjutan fungsi dan manfaat sumberdaya hutan yang optimal dan peningkatan IPM yang bersifat fleksibel, partisipatif dan akomodatif. Surat perjanjian kerja sama (SPKS) ditetapkan oleh kedua pihak dalam rangka mencapai tujuan PHBM berdasarkan pada komoditas. Komoditas kopi merupakan komoditas yang paling banyak dikembangkan dalam kerangka kemitraan PHBM.

Perlahan-lahan, program PHBM melalui budi daya tanaman kopi di sebagian besar hutan lindung Perum Perhutani wilayah Jabar-Banten memberikan dampak positif terhadap aspek sosial, ekonomi dan ekologi. Pihakpihak yang berkonflik telah mencapai konsensus bersama melalui negosiasi sehingga terbentuk Lembaga Masyarakat Desa Hutan (LMDH) yang terdiri atas para petani kopi (Mustapit 2011). Selain itu, PHBM bertujuan untuk meningkatkan pendapatan para petani serta menambah kesempatan bekerja di pedesaan (Budidarsono dan Wijaya 2003; Puspitojati dan Saefudin 2012).

Pembudi dayaan tanaman kopi melalui sistem naungan atau model agroforestri di desa-desa hutan yang berada di wilayah kerja Perum Perhutani bertujuan untuk menumbuhkembangkan kesadaran masyarakat dalam menjaga dan meningkatkan fungsi lindung disamping meningkatkan kesejahteraan masyarakat itu sendiri (Suprapto 2014). Pada pembangunan sektor kehutanan, sistem agroforestri berkontribusi dalam memperkaya keanekaragaman hayati, menyediakan sumber kayu dan non kayu, memelihara integritas ekosistem, meningkatkan kualitas tanah dan air, serta menyimpan cadangan karbon terestrial (Ruark et al. 2003). 
Selain berperan sebagai zona penyangga, beberapa penelitian terdahulu mengungkap berbagai layanan ekosistem yang dihasilkan melalui pengembangan sistem agroforestri berbasis kopi di sekitar kawasan hutan, antara lain (1) penyediaan habitat fauna dan avifauna (O'Connor et al. 2005; Hadiyanti 2014) dan konservasi keanekaragaman hayati dengan terbangunnya koridor-koridor lanskap (Moguel and Toledo 1999; Perfecto et al. 2005), (2) pengaturan tata air melalui penghambatan limpasan permukaan oleh tajuk pohon dan serasah serta penurunan tingkat erosi (Budidarsono dan Wijaya 2003; Hadiyanti 2014), (3) perbaikan kondisi sumber mata air (Hadiyanti 2014), (4) pemeliharaan kandungan bahan organik tanah, (5) pengaturan iklim lokal melalui proses penyerapan dan penyimpanan cadangan karbon dioksida dengan adanya keanekaragaman pohon penaung (Van Noordwijk et al. 2002), serta (6) pengendalian hama secara terpadu yang dilakukan oleh semut, burung dan kelelawar yang tinggal pada sistem dimaksud (MEA 2005) dan layanan penyerbukan (Klein et al. 2003).

Sejauh ini, studi tentang layanan ekosistem pada sistem agroforestri dengan pengembangan budi daya kopi di kawasan hutan lindung yang berbatasan dengan kawasan konservasi masih terbatas. Sementara, riset parsial mengenai jasa lingkungan pada sistem pembudi dayaan kopi dan sistem agroforestri berbasis kopi telah banyak dilakukan di Indonesia. Di sisi lain, para pemangku kepentingan kurang mengapresiasi dan memiliki keterbatasan dalam memahami (Ginoga et al. 2005) fungsi ekologis dan jasa lingkungan dari hutan lindung yang dikelola melalui pola kemitraan.

Desa Cisero merupakan desa penyangga pada kawasan konservasi Cagar Alam Gunung Papandayan yang secara geografis terletak di hulu DAS Cimanuk. Desa Cisero tidak lepas dari tekanan yang mengancam lingkungan sehubungan posisinya sebagai zona penyangga kawasan konservasi. Akan tetapi, masyarakat Desa Cisero memiliki kearifan tersendiri dalam mengelola hutan dan lingkungannya, salah satunya melalui pembudi dayaan tanaman kopi. Dalam rangka mengungkap layanan ekosistemnya, maka dilakukan penelitian pada sistem agroforestri yang dikembangkan dengan budi daya kopi di Desa Cisero yang terdiri atas hutan lindung di wilayah Perum Perhutani dan di lahan milik masyarakat.

Penelitian yang dilakukan pada sistem agroforestri berbasis kopi di Desa Cisero ini bertujuan untuk mengetahui, mengungkap dan mengidentifikasi :

a) Layanan ekosistem, baik jenis maupun bentuknya;

b) Pengetahuan masyarakat mengenai layanan ekosistem; dan

c) Strategi pengelolaan lingkungan untuk mempertahankan layanan ekosistem. 


\section{METODOLOGI}

\subsection{Lokasi kajian dan waktu penelitian}

Studi ini dilakukan di Desa Cisero yang terletak di wilayah Garut Selatan dan berada di sebelah timur Cagar Alam Gunung Papandayan. Berdasarkan profil Desa Cisero tahun 2015, desa ini terbagi atas 3 dusun, 7 rukun warga (RW) dan 37 rukun tetangga (RT). Lokasi penelitian difokuskan pada dua dusun, yakni Dusun I dan II (RW 01 s.d. RW 04).

Metode kualitatif digunakan untuk mengeksplorasi pandangan informan tentang jenis dan bentuk layanan ekosistem pada sistem agroforestri kopi di Desa Cisero. Dalam rangka mengklarifikasi informasi yang didapat dari hasil wawancara, maka dilakukan survei dan observasi. Metode kualitatif dilakukan pula untuk menggali informasi mengenai praktek atau pengelolaan agroforestri yang dikembangkan dengan membudi dayakan tanaman kopi. Sementara itu, metode kuantitatif melalui teknik survei dengan menggunakan instrumen kuesioner digunakan untuk mengumpulkan data dan informasi yang dapat menjelaskan pengetahuan masyarakat tentang layanan ekosistem sehingga dapat dianalisis secara statistik.

Informan dipilih berdasarkan hasil perumusan hasil studi pendahuluan. Hal yang dipertimbangkan dalam pemilihan informan adalah representativitas dan relevansi informasi yang akan dihimpun. Tabel 1 memperlihatkan daftar key informant dalam penelitian.

Tabel 1. Informan kunci.

\begin{tabular}{|c|c|}
\hline No & Daftar Informan Kunci dari Berbagai Stakeholder \\
\hline 1 & Kaur Pengelolaan Hutan Bersama Masyarakat pada Perum Perhutani KPH Garut \\
\hline 2 & Pengurus Lembaga Masyarakat Desa Hutan Wanariksa, Cisero \\
\hline 3 & $\begin{array}{l}\text { Kepala Seksi Perlindungan Hutan dan Konservasi Sumber Daya Hutan pada Dinas } \\
\text { Kehutanan Kabupaten Garut }\end{array}$ \\
\hline 4 & Kepala Seksi Konservasi Lahan dan Air pada Dinas Perkebunan Kabupaten Garut \\
\hline 5 & $\begin{array}{l}\text { Tokoh masyarakat, perangkat desa, petani penggarap serta pemilik lahan agroforestri } \\
\text { kopi Desa Cisero Kecamatan Cisurupan }\end{array}$ \\
\hline
\end{tabular}

\subsection{Prosedur analisis data}

Jenis dan bentuk layanan ekosistem pada sistem agroforestri berbasis kopi merupakan data kualitatif yang dianalisis berdasarkan klasifikasi layanan ekosistem (MEA 2005). Survei dilakukan untuk mengungkap pengetahuan terhadap layanan ekosistem dengan menggunakan instrumen berupa kuesioner. Topik pertanyaan di dalam kuesioner, meliputi 1) karakteristik responden, 2) rumah tinggal, 3) pemilikan/penguasaan lahan dan pengusahaan mata pencaharian, 4) pemilikan sumber daya (aset) ekonomi lainnya, 5) pendapatan 1 (satu) tahun terakhir, 6) organisasi/kelembagaan dan ketokohan, 7) interaksi 
ekologis dan layanan ekosistem sistem agroforestri berbasis kopi, 8) pengetahuan tentang karakteristik pohon dan manfaatnya pada sistem agroforestri kopi, serta 9) pengetahuan tentang keanekaragaman hayati dan layanan ekosistemnya. Jumlah responden ditentukan dengan menggunakan rumus Lynch et al. (1974), diperoleh sebanyak 82 orang.

Wawancara terhadap informan dilakukan untuk mengetahui strategi perlindungan dan pengelolaan dalam rangka mempertahankan layanan ekosistem. Data dan informasi dari hasil wawancara dianalisis menggunakan Model DPSIR (Driver - Pressure - State -Impact - Response) yang dikembangkan pada tahun 2003 oleh Organization For Economic Cooperation and Development (OECD).

\section{HASIL DAN PEMBAHASAN}

\subsection{Jenis dan bentuk layanan ekosistem pada sistem agroforestri berbasis kopi di Desa Cisero, Garut}

\subsubsection{Jasa penyediaan}

Berdasarkan hasil penelitian di Desa Cisero, bentuk jasa penyediaan pada sistem agroforestri kopi meliputi sumber pangan, energi, pakan dan bahan bangunan. Sejalan dengan pernyataan Mendez dan Bacon (2006) bahwa pengembangan sistem agroforestri kopi dengan aneka pohon dapat memberikan keteduhan. Sistem tersebut dapat pula menghasilkan produk lain seperti apa yang diperoleh dari ekosistem hutan, misalnya bahan bangunan, tanaman buah, kayu bakar, dan tanaman obat.

Jasa penyediaan dan manfaat yang diterima masyarakat dari sistem tersebut merupakan sumber daya hayati yang terdiri atas tanaman musiman dan tahunan. Data produksi dan produktivitas kopi di Desa Cisero yang dibudi dayakan oleh masyarakat yang tergabung dalam Lembaga Masyarakat Desa Hutan Wanariksa pada periode 2010-2014 dapat dilihat pada Tabel 2.

Tabel 2. Hasil tanaman kopi di Desa Cisero.

\begin{tabular}{lrrrrr}
\hline Komoditas Kopi di Desa Cisero & 2010 & 2011 & 2012 & 2013 & 2014 \\
\hline Luas (ha) & 47,36 & 110,00 & 110,00 & 110,00 & 110,00 \\
a. TBM (tanaman belum & & & & & \\
$\quad$ menghasilkan) & 33,00 & 50,00 & 34,75 & 16,75 & 16,75 \\
b. TM (tanaman menghasilkan) & 14,36 & 45,00 & 60,00 & 90,00 & 90,00 \\
c. TTR (tanaman tua dan rusak) & - & 14,00 & 15,25 & 3,25 & 3,25 \\
\hline Produksi (ton) & 21,827 & 64,800 & 96,000 & 115,000 & 122,400 \\
\hline Produktivitas (ton/ha) & 0,253 & 0,240 & 0,267 & 0,213 & 0,227 \\
\hline
\end{tabular}

Sumber: UPTD Dinas Perkebunan Wilayah Cikajang, Cisurupan dan Cigedug (2015) 
Di lahan perkebunan rakyat dimana sistem agroforestri dengan pengembangan tanaman kopi telah diterapkan, produktivitas komoditas tanaman pangan cenderung lebih tinggi jika dibandingkan dengan tanaman kopi. Hal ini karena preferensi masyarakat pemilik lahan yang mengutamakan tanaman-tanaman yang cepat menghasilkan. Sementara di kawasan hutan lindung, hasil komoditas bahan pangan yang diperoleh lebih rendah karena ketentuan pengelolaan yang sangat terbatas (Gambar 1).

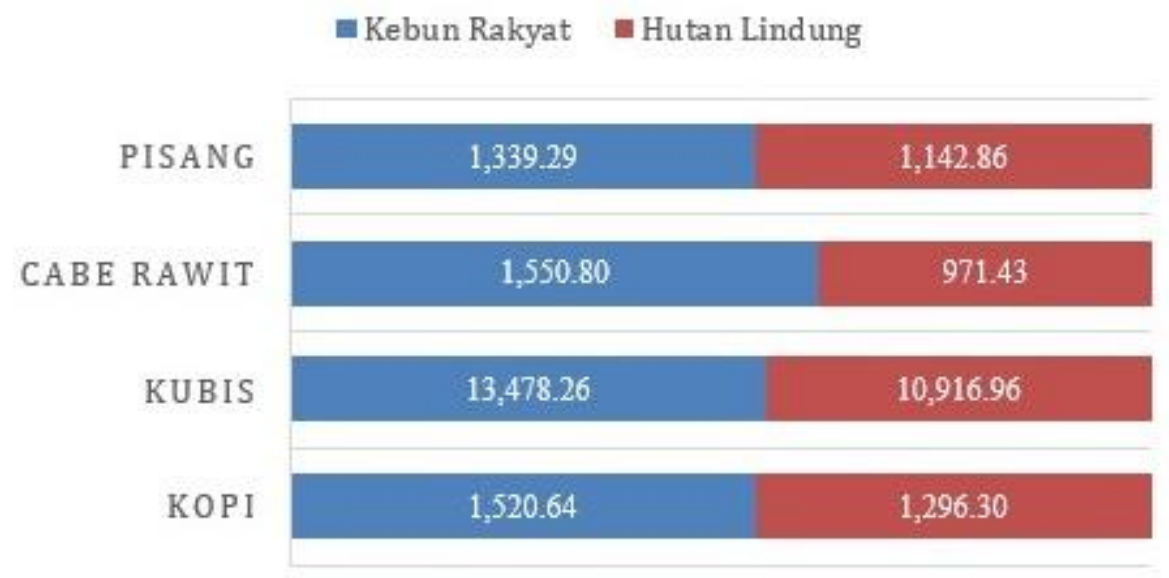

Gambar 1. Perbandingan produktivitas komoditi pada sistem agroforestri kopi dalam $\mathrm{kg} / \mathrm{ha}$ /tahun (Sumber: Analisis data primer 2015).

Jenis hijauan seperti daun pisang, lamtoro, sobsi, dadap dan nangka dimanfaatkan oleh masyarakat sebagai pakan ternak. Jenis pohon tersebut merupakan jenis pohon penaung kopi yang umumnya berada di lahan milik. Adapun jenis rumput dan tumbuhan liar yang digunakan masyarakat untuk mencukupi kebutuhan pakan dari kawasan hutan lindung, antara lain balakaciut (Galinsoga parviflora), lamjani, carulang (Eleusine indica), lameta (Leersia hexandra), kakawatan (Cynodon dactylon), jukut haseum (Polygonum nepalense), rumput tenggo (Foeniculum vulgare), babadotan (Ageratum conyzoides), terong anjing (Heliotropium indicum) dan jukut pait (Axonopus compressus).

Layanan ekosistem langsung lainnya yang diperoleh masyarakat dengan adanya pohon penaung adalah sebagai kayu bakar (sumber energi). Jenis pohon yang bermanfaat sebagai sumber energi adalah lamtoro (Leucaena leucocephala), eukaliptus (Eucalyptus sp.), suren (Toona sureni) dan kaliandra (Caliandra calothyrsus). Masyarakat memanfaatkan bagian-bagian pohon seperti cabang dan ranting yang jatuh ke lantai tanah, maupun dari hasil penjarangan.

Sementara itu, tanaman eukaliptus yang berada di lahan kopi milik masyarakat sewaktu-waktu dapat dimanfaatkan menjadi bahan bangunan. Berdasarkan hasil survei terhadap masyarakat, populasi eukaliptus di lahan kopi 
mencapai 80,49\% dari keseluruhan populasi pohon penaung kopi. Selain untuk bahan bangunan, tanaman tisuk, suren, dan eukaliptus dimanfaatkan oleh 4,54\% responden untuk membuat kandang ternak.

\subsubsection{Jasa pengaturan}

Jasa pengaturan adalah manfaat dari pengaturan proses-proses yang terjadi di dalam ekosistem (MEA 2005). Contoh jasa pengaturan, antara lain meliputi pengaturan dan penjernihan air, pengaturan penyakit dan pengaturan iklim. Penduduk di Desa Cisero memiliki persepsi bahwa kebun kopi melalui sistem naungan mampu menjalankan dan mengatur tata air $(23,17 \%$ responden). Perambahan merupakan salah satu faktor yang mengakibatkan lahan hutan perlahan-lahan menjadi terbuka. Program PHBM di kawasan hutan lindung yang memadukan tanaman kehutanan dan komoditas kopi, secara perlahan-lahan menunjukkan perbaikan kondisi tutupan lahan. Disamping menjaga tanaman pokok kehutanan, budi daya kopi merupakan cara masyarakat memanfaatkan lahan di kawasan hutan lindung.

Pada sistem agroforestri kopi, siklus air dipengaruhi oleh keberadaan pohon. Pohon berperan dalam untuk meningkatkan intersepsi hujan, pengurangan limpasan permukaan, retensi lebih besar dari air di dalam tanah, dan peningkatan infiltrasi (Jose 2009). Jasa pengaturan lainnya yang dirasakan masyarakat adalah perbaikan iklim mikro, contohnya kualitas udara di sekitar desa menjadi lebih sejuk $(20,73 \%$ responden $)$.

Mengenai penurunan tingkat erosi, dilakukan perhitungan dengan menggunakan persamaan USLE, baik di lahan perkebunan rakyat maupun di kawasan hutan lindung. Pada Tabel 3 dapat dilihat komparasi tingkat bahaya erosi pada kedua lokasi tersebut.

Tabel 3. Pendugaan erosi yang terjadi pada tata guna lahan di Desa Cisero.

\begin{tabular}{lcccc}
\hline \multicolumn{1}{c}{ Faktor Pendugaan Erosi } & \multicolumn{2}{c}{$\begin{array}{c}\text { Komoditi sayuran } \\
\text { (hortikultura) }\end{array}$} & \multicolumn{2}{c}{ Komoditi kopi } \\
\multicolumn{1}{c}{ (A = R K LS C P) } & KR & HL & KR & HL \\
\hline Erosivitas hujan (R) & 210,70 & 249,25 & 210,70 & 249,25 \\
Jenis tanah K) & 0,13 & 0,31 & 0,13 & 0,31 \\
Panjang dan kemiringan lereng (LS) & 1,40 & 3,10 & 1,40 & 3,10 \\
Penggunaan lahan (C) & 0,80 & 0,80 & 0,60 & 0,60 \\
Tindakan konservasi (P) & 0,30 & 0,20 & 0,30 & 0,20 \\
NILAI E (Ton/Ha/Tahun) & 9,20 & 38,32 & 6,90 & 28,74 \\
Tingkat Bahaya Erosi yang & 9,60 & 9,60 & 9,60 & 9,60 \\
Diperkenankan (TSL) & & & & \\
Tingkat Bahaya Erosi (TBE) & 0,96 & 3,99 & 0,72 & 2,99 \\
= A/TSL & & & & \\
\hline
\end{tabular}

Sumber : Data sekunder diolah (2015) 
Secara tidak langsung, penurunan tingkat bahaya erosi merupakan dampak yang ditimbulkan dari adanya program alih komoditi komoditas hortikultura ke tanaman kopi. Pola aliran air hujan yang jatuh ke tanah dapat diubah melalui keberadaan tanaman pelindung kopi. Jatuhan air hujan tertahan oleh tajuk pohon dan sebagian air hujan mengalami kondensasi sehingga tidak mencapai permukaan tanah. Batang dan cabang-cabang tanaman mengalirkan air hujan yang tertahan pada tajuk tanaman. Tumbuhan bawah yang menghalangi terjadinya erosi akibat percikan air hujan yang jatuh dari daun ke tanah. Peran lain ditunjukkan oleh serasah yang mampu melindungi tanah dari percikan air. Di samping itu, kelangsungan hidup organisme tanah maupun makhluk hidup kecil lainnya dapat terjamin dengan keberadaan serasah.

\subsubsection{Jasa pendukung dan kultural}

Berdasarkan MEA (2005), layanan ekosistem berupa jasa pendukung meliputi produksi oksigen, pembentukan tanah, siklus nutrisi dan lainnya. Sebanyak 24,39\% responden menyatakan bahwa kesuburan tanah dapat terpelihara melalui budi daya tanaman kopi yang dipadukan dengan pepohonan. Serasah (dalam bahasa Sunda kalakay) tidak dibuang seluruhnya, namun dikembalikan ke tanah dengan cara dikubur. Nansamba (2009) menyatakan bahwa petani memiliki pengetahuan dan kesadaran dalam memanfaatkan pohon penaung kopi terutama dalam mendukung daur nutrisi melalui pemanfaatan kembali serasah dari daun atau cabang yang dipangkas.

Menurut Moguel and Toledo (1999) dan Perfecto et al. (2005), budi daya kopi dengan sistem naungan (shaded coffee systems) merupakan sistem agroforestri yang mampu menjamin serta memberikan peluang yang besar untuk meningkatkan keanekaragaman hayati dibandingkan dengan praktek pertanian tradisional. Beberapa dampak positif dari perkembangan komoditas kopi di lahan milik masyarakat dan kondisi tutupan lahan di kawasan hutan Desa Cisero yang semakin membaik pasca kejadian perambahan adalah kembali eksisnya komponen biotik yang dulu mengisi ekosistem di desa tersebut. Berdasarkan hasil studi, diperoleh data dan informasi mengenai keanekaragaman jenis fauna.

Jasa kultural dalam layanan ekosistem meliputi manfaat edukasi, rekreasi, pengayaan spiritual, pengalaman kognitif, dan pengalaman estetik (MEA 2005). Lembaga Masyarakat Desa Hutan Wanariksa telah memiliki sarana pertemuan dan pembelajaran yang berlokasi di petak 53c hutan lindung Perum Perhutani yang dibangun pada tahun 2008. Tempat tersebut digunakan untuk kegiatan pertemuan rutin bulanan maupun insidental yang diselenggarakan oleh dinas atau instansi terkait, misalnya penyuluhan dan sekolah lapang. Kegiatan pembelajaran tersebut memungkinkan terjadinya alih pengetahuan serta sharing informasi dari instruktur dan/atau petani yang telah berpengalaman dan memiliki 
pengetahuan baik mengenai teknis budi daya kopi dan pelestarian sumber daya hutan. Selain itu, para anggota kelompok dapat langsung mempraktekkan pengetahuan yang diperolehnya.

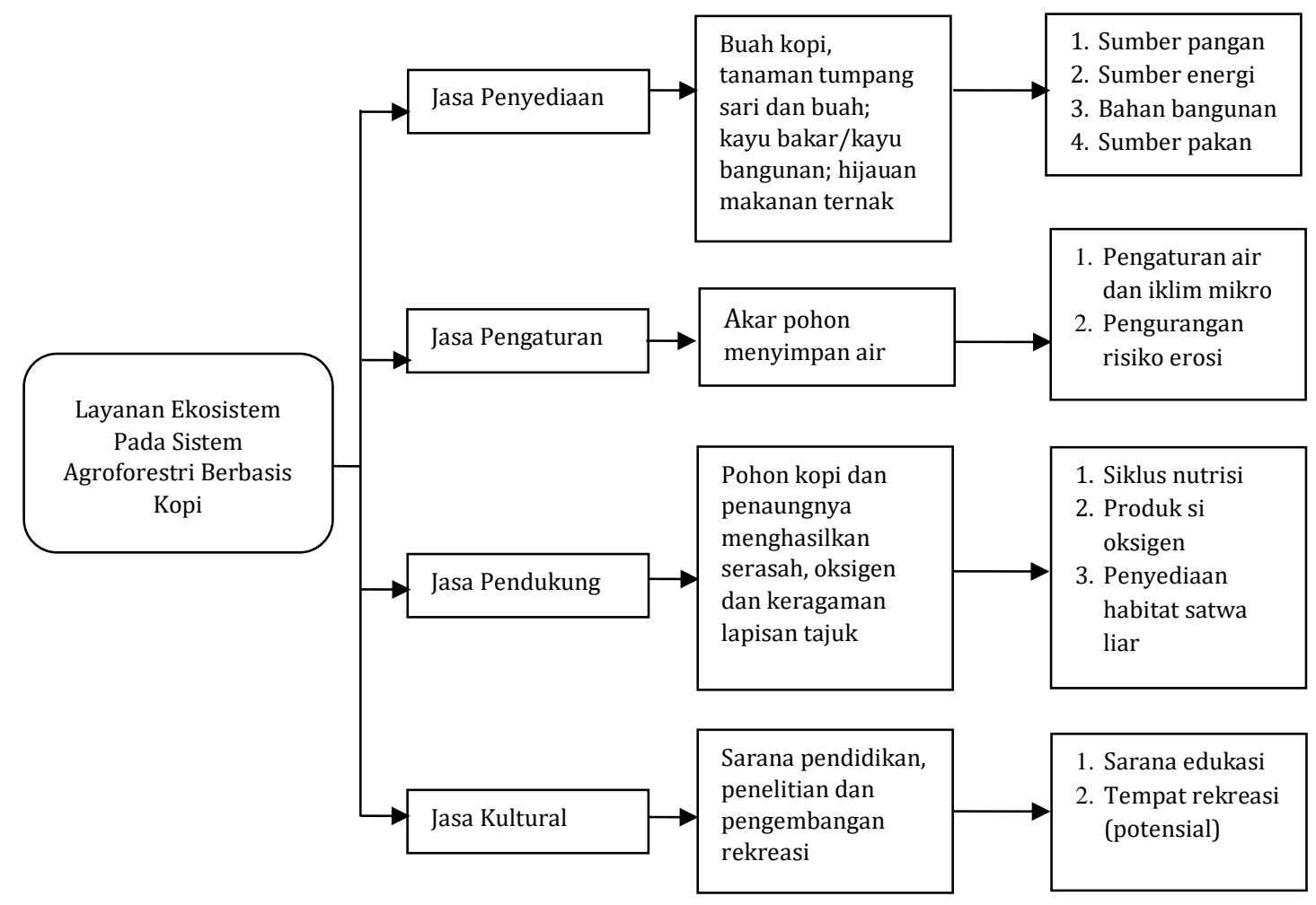

Gambar 2. Jenis dan bentuk layanan pada sistem agroforestri berbasis kopi di Desa Cisero, Garut (Sumber : Analisis data primer dan sekunder 2015).

\subsection{Pengetahuan masyarakat}

\subsubsection{Pengetahuan masyarakat mengenai layanan ekosistem pohon penaung kopi}

Di Desa Cisero, masyarakat mengetahui sebanyak 27 dari 37 spesies pohon pada sistem agroforestri kopi yang dapat memberikan manfaat.

\subsubsection{Layanan penyediaan}

Umumnya, bentuk layanan penyediaan spesies pohon bagi masyarakat antara lain sebagai bahan pangan, bahan bakar (energi) dan material bangunan. Adapun masyarakat yang mengambil manfaat dari daun beberapa spesies pohon untuk memenuhi kebutuhan (pakan) ternak. Jenis pohon untuk pakan ternak antara lain lamtoro, sobsi dan kaliandra. Beberapa spesies pohon yang memberikan layanan penyediaan, terlihat pada Gambar 3. 


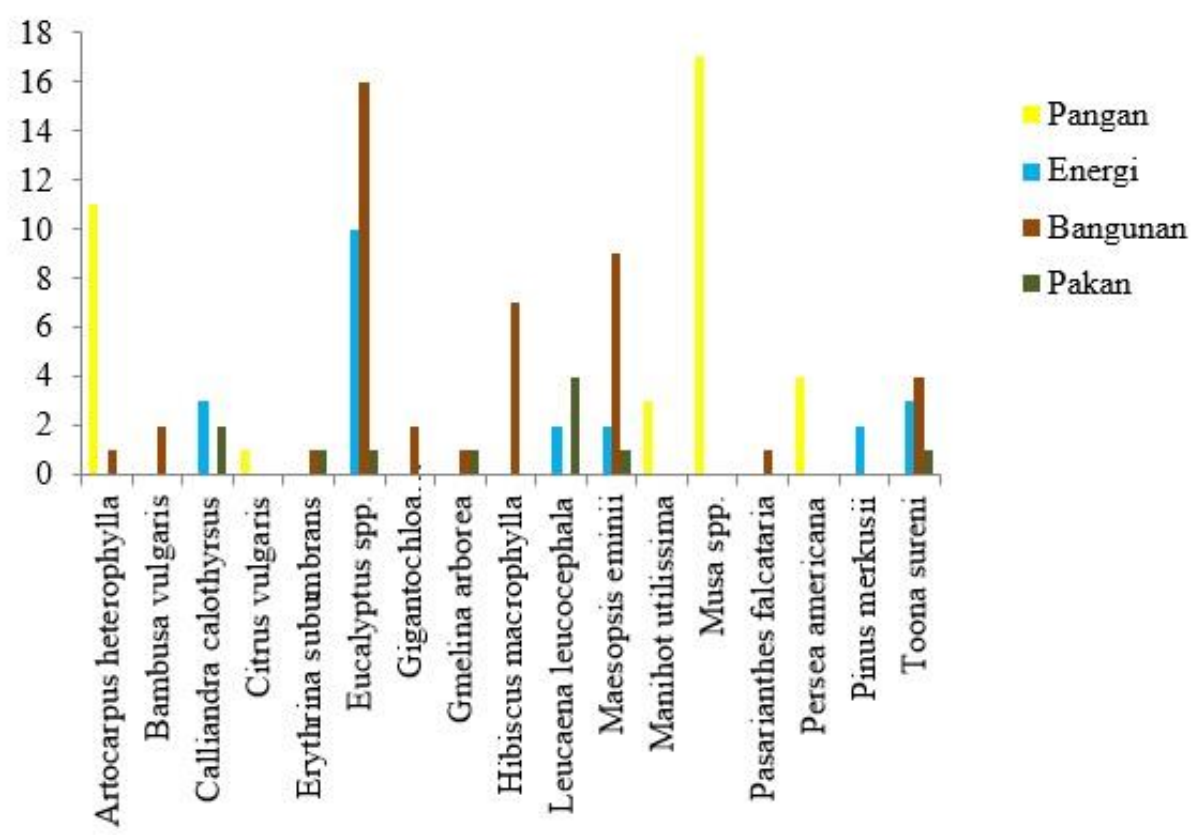

Gambar 3. Berbagai spesies tanaman pada sistem kopi di lahan milik dikaitkan dengan jasa penyediaan berdasarkan jumlah pernyataan masyarakat.

(Sumber : Analisis data primer dan sekunder 2015)

\subsubsection{Layanan pengaturan}

Jenis layanan ekosistem lain yang masih berkaitan dengan pengetahuan lokal masyarakat tentang jenis dan manfaat pohon pada sistem agroforestri kopi adalah jasa pengaturan. Tabel $\mathbf{4}$ menunjukkan pengetahuan masyarakat Desa Cisero terhadap jasa pengaturan.

Masyarakat mengetahui bahwa untuk mendukung produktivitas tanaman kopi perlu adanya pohon-pohon peneduh dalam satu sistem. Dari hasil survei diperoleh bahwa masyarakat (91,46\% responden) mengetahui pohon-pohon berfungsi sebagai pohon peneduh/penaung dan pelindung.

Tabel 4. Pengetahuan masyarakat tentang pohon dikaitkan dengan jasa pengaturan.

\begin{tabular}{lcrrrrr}
\hline \multicolumn{1}{c}{$\begin{array}{c}\text { Pengetahuan tentang pohon dan } \\
\text { jasa pengaturan }\end{array}$} & \multicolumn{2}{c}{ Ya } & \multicolumn{2}{c}{ Tidak } & \multicolumn{2}{c}{ Tidak Tahu } \\
\cline { 2 - 7 } & $\mathbf{N}$ & $\mathbf{0}$ & $\mathbf{n}$ & $\mathbf{\%}$ & $\mathbf{n}$ & $\mathbf{\%}$ \\
\hline $\begin{array}{l}\text { Keberadaan pohon menunjang } \\
\text { produktivitas kopi }\end{array}$ & 75 & 91,46 & 1 & 1,22 & 6 & 7,32 \\
$\begin{array}{l}\text { Pemeliharaan dan peningkatan } \\
\text { kesuburan tanah karena adanya penaung } \\
\text { kopi }\end{array}$ & 70 & 85,37 & 7 & 8,54 & 5 & 6,10 \\
$\begin{array}{l}\text { Pohon penaung kopi membantu } \\
\text { melestarikan air }\end{array}$ & 60 & 73,17 & 13 & 15,85 & 9 & 10,98
\end{tabular}




\begin{tabular}{|c|c|c|c|c|c|c|}
\hline \multirow{2}{*}{$\begin{array}{l}\text { Pengetahuan tentang pohon dan } \\
\text { jasa pengaturan }\end{array}$} & \multicolumn{2}{|c|}{ Ya } & \multicolumn{2}{|c|}{ Tidak } & \multicolumn{2}{|c|}{ Tidak Tahu } \\
\hline & $\mathbf{N}$ & $\%$ & $\mathbf{n}$ & $\%$ & $\mathbf{n}$ & $\%$ \\
\hline $\begin{array}{l}\text { Serasah daun pohon penaung baik untuk } \\
\text { menyuburkan tanah }\end{array}$ & 79 & 96,34 & 1 & 1,22 & 2 & 2,44 \\
\hline $\begin{array}{l}\text { Penurunan risiko erosi melalui } \\
\text { minimisasi limpasan permukaan oleh } \\
\text { serasah }\end{array}$ & 22 & 26,83 & 33 & 40,24 & 27 & 32,93 \\
\hline $\begin{array}{l}\text { Pohon dapat mengurangi risiko erosi } \\
\text { tanah }\end{array}$ & 60 & 73,17 & 8 & 9,76 & 14 & 17,07 \\
\hline
\end{tabular}

Pohon penaung kopi terbagi menjadi 2 kategori, yakni penaung tetap dan penaung sementara. Spesies pohon penaung tetap antara lain dadap (Erythrina subumbrans), lamtoro (Leucaena leucocephala), albasiah (Pasarianthes falcataria), dan cemara (Casuarina spp.). Secara spesifik, tanaman penaung sementara tidak ditentukan jenisnya, melainkan harus dipertimbangkan syaratsyarat pohon pelindung yang sesuai dengan kondisi fisik lingkungan dan agroklimat setempat.

Kontribusi spesies pohon pelindung yang mampu memelihara dan meningkatkan kesuburan tanah ditunjukkan oleh $85,37 \%$ responden. Secara berturut-turut dari mulai yang terendah, yakni albasiah dan eukaliptus $(8,64 \%)$, pisang $(9,76 \%)$, nangka $(13,41 \%)$, dadap $(15,85 \%)$, dan suren (Toona sureni) sebesar (18,29\%) (Gambar 4). Petai cina, bambu, dan sobsi merupakan spesies pohon lainnya yang disebutkan masyarakat. Masyarakat pula mengetahui peran serasah dari spesies-spesies pohon tersebut. Adanya serasah yang dihasilkan dari pohon membantu meningkatkan kesuburan tanah. Sekitar 96,34\% masyarakat menyatakan bahwa serasah daun pohon penaung yang jatuh, kemudian terurai (terdekomposisi) dapat membantu menyuburkan tanah. Beer (1988) menyatakan bahwa dalam hal pemeliharaan kesuburan tanah pada kebun kopi, peran pohon penaung dalam memproduksi serasah lebih penting jika dibandingkan dengan kemampuannya dalam memfiksasi nitrogen.

Sebanyak 73,17\% responden mengetahui peran pohon dalam perlindungan air. Selain itu 7,31\% masyarakat menyatakan bahwa akar pohon dari jenis bambu, nangka, alpukat, dan pisang yang berada pada sistem agroforestri kopi membantu menyimpan air. Eukaliptus, suren dan kihujan merupakan spesies lain yang tidak dominan. Sebanyak $73,17 \%$ responden juga mengetahui kontribusi pepohonan dalam pencegahan atau pengurangan risiko erosi serta longsor. Dari hasil penelitian, penurunan tingkat erosi kerap kali dihubungkan dengan keberadaan tanaman eukaliptus $(18,29 \%)$. 


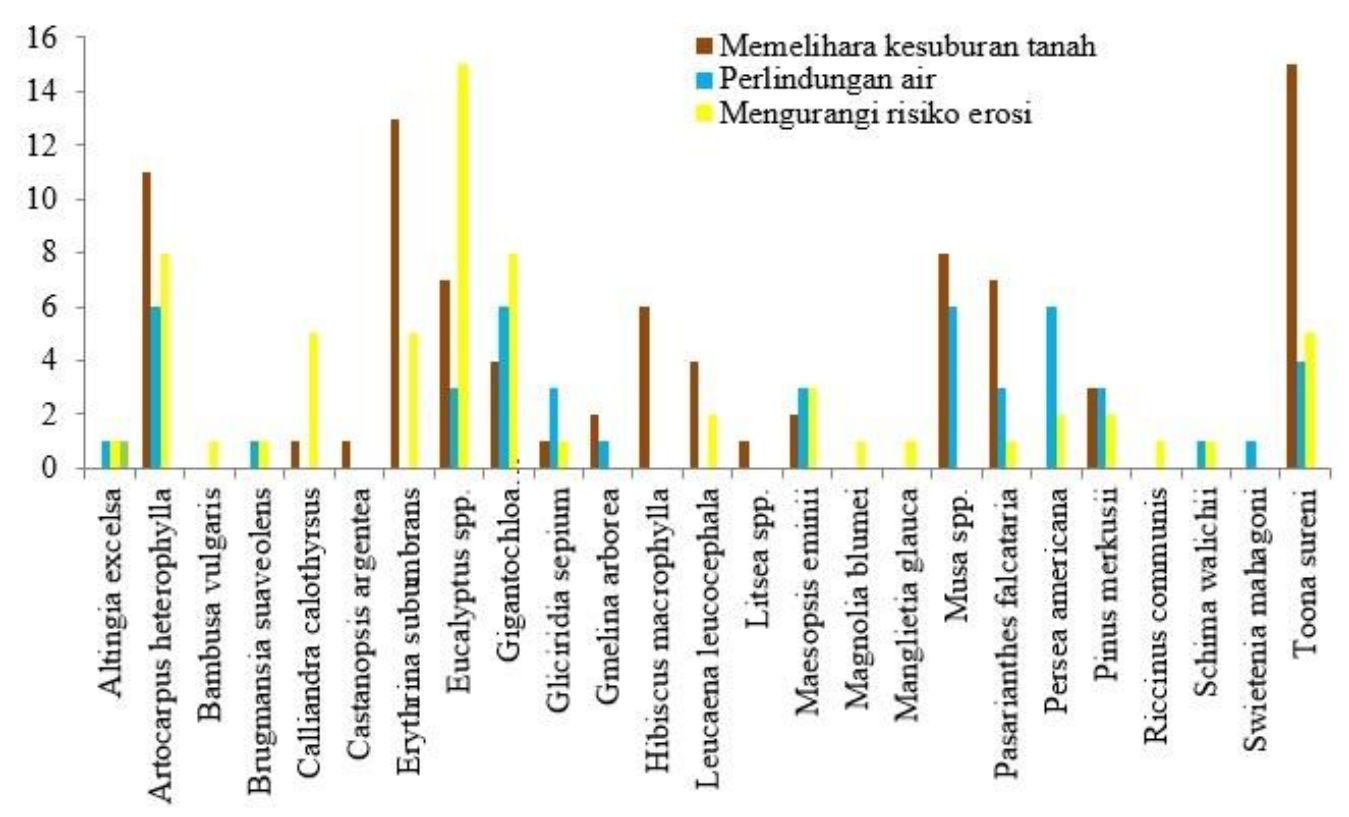

Gambar 4. Persepsi masyarakat mengenai spesies pohon dan layanan ekosistem berupa kasa pengaturan di Desa Cisero.

(Sumber : Analisis data primer dan sekunder 2015)

Peningkatan kesuburan tanah, pemeliharaan kelembaban tanah dan pencegahan erosi, serta penyediaan sumber pakan ternak pada sistem agroforestri kopi harus dipertimbangkan sebagai syarat cover crop yang diterapkan. Tanaman penutup tinggi yang dapat diaplikasikan pada sistem tersebut antara lain dadap, petai cina, albasiah, kihujan dan bambu. Kaliandra merupakan contoh tanaman penutup sedang.

\subsection{Pengetahuan masyarakat terhadap layanan ekosistem dari keberadaan satwa liar}

Kegunaan setiap jenis pohon yang berada pada lahan garapan diidentifikasi oleh petani kopi dalam upaya pelestarian jenis-jenis satwa liar. Dibandingkan dengan kopi monokultur, sistem agroforestri kopi dengan model naungan atau multistrata memberi daya dukung yang lebih tinggi terhadap keanekaragaman hayati (O'Connor et al. 2005).

Sebanyak 65,85\% responden pernah menjumpai satwa liar di lahan agroforestri kopi yang digarapnya. Umumnya masyarakat (43,90\% responden) menjumpai satwa liar sedang melakukan aktivitas makan (feeding activities). Berdasarkan hasil survei, satwa-satwa liar yang dimaksud 23 spesies dari kelas Aves dan 5 spesies dari kelas Mamalia. 
Cucak kutilang (Pycnonotus aurigaster) adalah spesies burung paling sering disebutkan dan dijumpai oleh masyarakat $(17,07 \%)$. Jenis burung lain yang disebutkan antara lain tekukur (Streptopelia chinensis) sebesar 6,10\%, toed (Lanius schach) sebesar 10,98\% dan kacamata (Zosterops spp.) sebesar 12,20\%. Selain itu, terdapat spesies mamalia yang dijumpai sedang melakukan aktivitas makan. Sebanyak 39,02\% responden menyebutkan pernah menjumpai musang (Paradoxurus hermaproditus) di lahan garapan mereka. Adanya kotoran (feses) merupakan salah satu indikasi bagi responden untuk mengenali keberadaan musang. Musang kerap kali memakan buah kopi meskipun tidak mampu mencerna secara sempurna. Jenis mamalia lainnya adalah tupai (Tupaia javanica). Disamping musang dan tupai, 4 orang responden menuturkan bahwa mereka pernah berjumpai dengan surili (Presbytis comata). Hewan liar tersebut menampakkan diri pada hutan lindung yang berbatasan dengan kawasan konservasi Cagar Alam Gunung Papandayan. Biasanya, hewan tersebut terlihat di waktu pagi dan menjelang malam hari. Surili menyukai tanaman kacang merah sebagai makanannya.

Dikorelasikan dengan perilakunya, 19,51\% masyarakat mengetahui bahwa satwa-satwa liar membuat sarang di atas pohon pada kebun kopi mereka (Gambar 5). Tiga spesies burung yang sering menggunakan pohon untuk bersarang antara lain cucak kutilang, kacamata dan toed. Spesies pohon yang digunakan untuk bersarang diantaranya eukaliptus, suren, nangka, pinus dan kopi.

Persepsi positif masyarakat mengenai keterkaitan antara keanekaragaman hayati dan pohon-pohon tertentu terbentuk karena pengetahuan dan kesadaran adanya spesies pohon yang memiliki dominansi tinggi pada sistem agroforestri kopi di Desa Cisero. Penelitian Cerdan et al. (2012) di Kosta Rika, mengungkap bahwa spesies Eucalyptus poeppigiana dengan tingkat dominansi yang tinggi merupakan faktor yang mempengaruhi persepsi masyarakat. Kelompok burung dan mamalia mendapatkan keuntungan yang lebih dengan adanya spesies eukaliptus tersebut. 


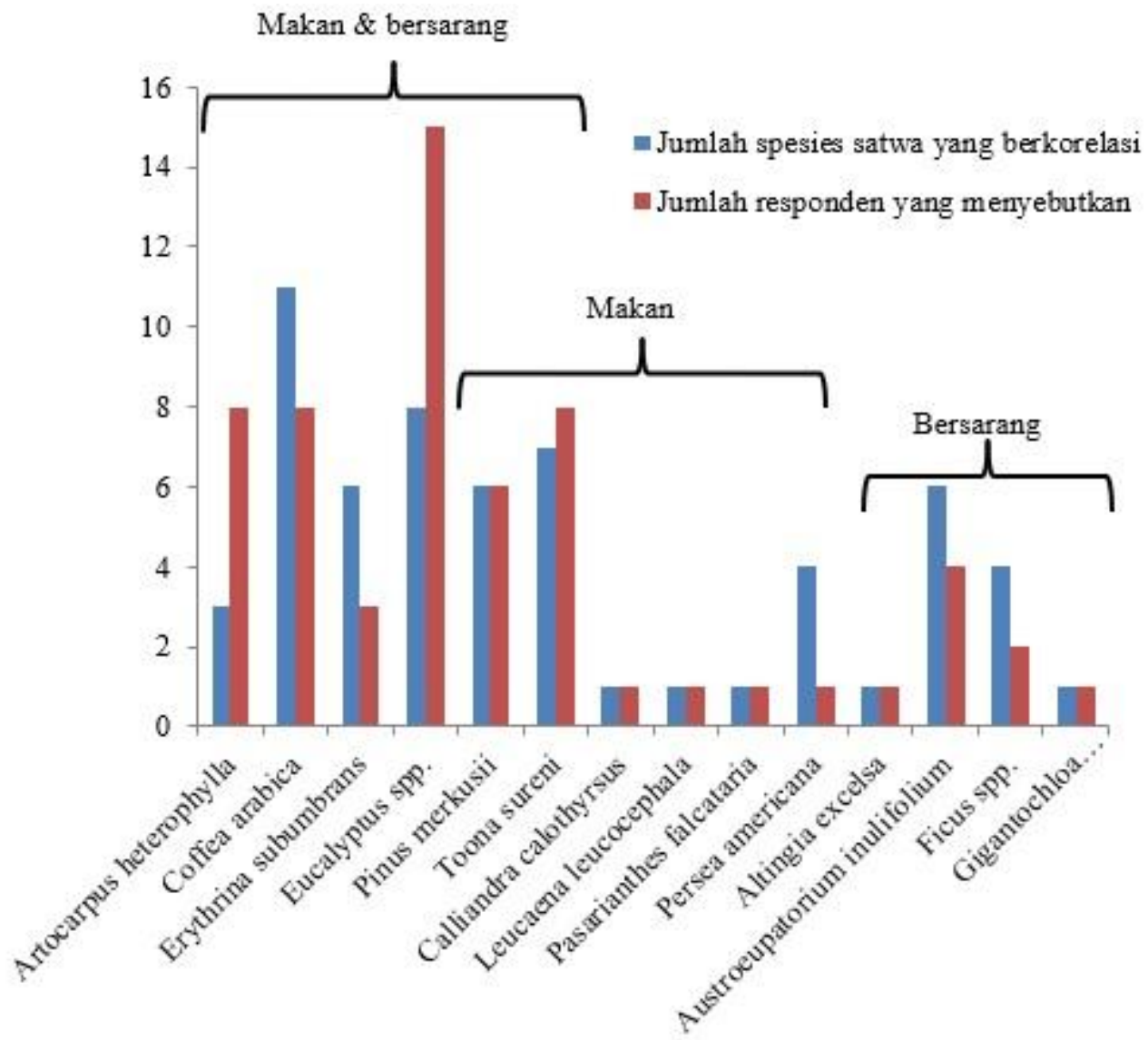

Gambar 5. Pengelompokan tanaman yang berasosiasi dengan keanekaragaman hayati. (Sumber : Analisis data primer dan sekunder 2015)

\subsection{Faktor yang mempengaruhi pengetahuan masyarakat}

Tingkat pengetahuan masyarakat dihitung dari setiap pernyataan dengan menggunakan skala Guttman dimana skor untuk jawaban Ya $=3$, Tidak $=1$ dan Tidak tahu $=0$. Skala yang digunakan memiliki range $0-100$, mengacu pada skala kategori Arikunto (2013). Dari hasil penelitian, maka secara umum tingkat pengetahuan masyarakat Desa Cisero terhadap layanan ekosistem pada sistem agroforestri berbasis kopi adalah baik dengan skor rata-rata 74,86. Masyarakat memiliki pengetahuan sangat baik terkait jasa penyediaan dari sistem tersebut (skor rata-rata 91,46), kemudian diikuti layanan ekosistem dari pohon penaung berupa jasa pengaturan (skor rata-rata 78,66 = baik) dan layanan ekosistem dari keberadaan hidupan liar (skor rata-rata 65,65 = baik). 
Jha (2012) mengungkapkan bahwa tingkat pengetahuan petani terhadap social forestry dipengaruhi oleh beberapa faktor, yakni usia, pendidikan, luasan kepemilikan lahan, pendapatan per tahun, partisipasi sosial, motivasi ekonomi, penggunaan sumber informasi dan inovasi. Kemudian, Iniesta-Arandia et al. (2015) mengelaborasi beberapa faktor yang mempengaruhi pengetahuan ekologi lokal atau local ecological knowledge (LEK), yakni sebagai berikut:

- lama interaksi dengan tata guna lahan;

- luas lahan yang digarap;

- profesi orang tua (apakah petani atau bukan);

- alih pengetahuan (dari orang tua, kerabat keluarga atau kelompoknya);

- turut serta membantu kegiatan pertanian orang tua, keluarga atau kelompoknya;

- pertukaran informasi berupa pengetahuan (dengan teman, keluarga atau

- kelompok); dan

- tingkat pendidikan.

\subsection{Strategi pengelolaan sistem agroforestri berbasis kopi}

Berdasarkan analisis DPSIR (Gambar 6), dapat dikemukakan beberapa rekomendasi dalam penelitian ini, antara lain :

1. Dalam menyelesaikan kasus perambahan di hutan lindung yang seharusnya dikelola sesuai NPKS budi daya kopi, maka seyogyanya Perum Perhutani harus mampu menegakkan hukum dan memberikan sanksi/hukuman bagi para perambah yang terbukti melanggar aturan berdasarkan temuan dan fakta lapangan. Kegiatan monitoring harus konsisten dan diagendakan secara rutin disertai pelaporan.

2. Untuk mengembalikan kondisi tutupan lahan yang telah terbuka dan mengalami kerusakan akibat aktivitas perambahan dan pengarusutamaan komoditas hortikultura, maka kegiatan reforestasi dan restorasi hutan lindung sebaiknya dilakukan dengan melibatkan berbagai stakeholder yang berwenang.

3. Dalam rangka menyelesaikan masalah permodalan budi daya kopi, maka pemberian stimulan kepada petani kopi harus disertai fasilitas berupa biaya/ongkos pemeliharaan (HOK) sampai tanaman kopi dapat menghasilkan (kurang lebih sampai 2,5-3 tahun). Koperasi petani kopi perlu dihidupkan kembali dengan harapan dapat menyokong modal finansial petani yang serius ingin menggarap lahan dan membudi dayakan komoditas kopi.

4. Program-program peningkatan kapasitas SDM petani kopi dan/atau anggota LMDH perlu dilanjutkan dan dilakukan secara kontinu. Hal ini penting untuk menambah wawasan serta memotivasi petani yang masih memiliki kekhawatiran mengalami kegagalan budi daya. 
5. Untuk meningkatkan manajemen data terkait pembudidayaan kopi, baik di lahan milik maupun di kawasan hutan lindung, khususnya di Desa Cisero dan umumnya Kabupaten Garut, maka perlu dilakukan pendokumentasian dan pengorganisasian data yang baik dari setiap stakeholder.

6. Secara preventif, petani harus mulai diberi pencerahan mengenai dampak penggunaan pupuk dan pestisida sintetis yang dapat mengancam keseimbangan ekosistem. Hal ini penting dalam upaya menciptakan sistem pertanian, perkebunan dan agroforestri yang ramah lingkungan dan berkelanjutan. 


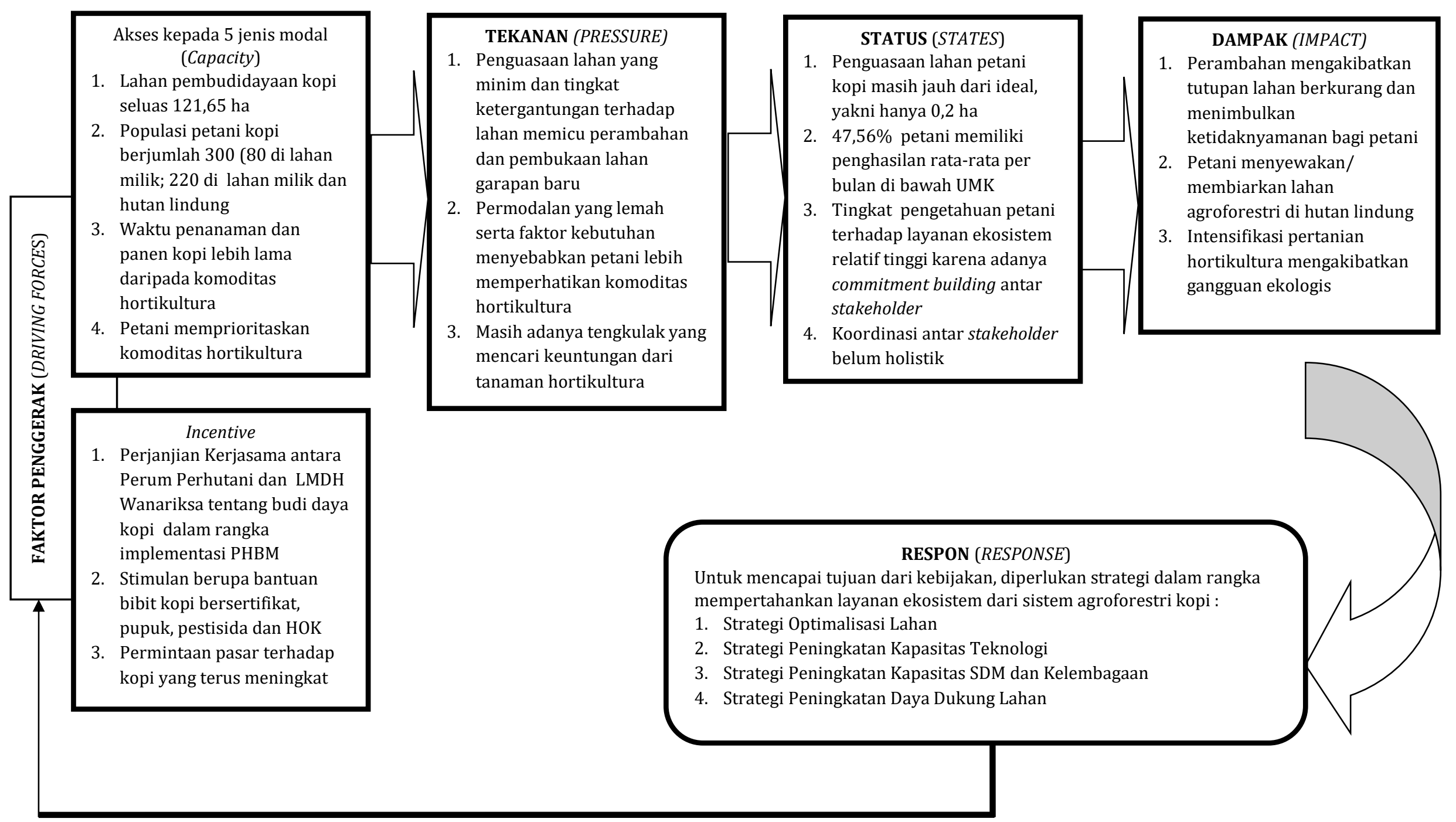

Gambar 6. Kerangka DPSIR pada sistem agroforestri berbasis kopi di Desa Cisero, Garut. 


\section{KESIMPULAN DAN SARAN}

Berdasarkan hasil dan pembahasan, dapat disimpulkan beberapa hal sebagai berikut :

1. Sistem agroforestri kopi di Desa Cisero menyediakan jenis layanan ekosistem meliputi jasa penyediaan, jasa pengaturan, jasa pendukung dan jasa kultural.

- Jasa penyediaan meliputi sumber pangan (berupa kopi, sayuran dan buahbuahan), sumber pakan ternak, sumber energi (kayu bakar) dan bahan bangunan. Di kawasan hutan lindung, terdapat keterbatasan untuk memanfaatkan sumber daya kayu karena adanya peraturan yang dibuat oleh Perum Perhutani.

- Jasa pengaturan meliputi tata air dan pengaturan iklim mikro serta pencegahan dan penurunan risiko erosi. Pohon penaung kopi memiliki kontribusi dalam menunjang jasa pengaturan. Peningkatan tutupan vegetasi memberikan dampak berupa peningkatan kualitas udara.

- Jasa pendukung meliputi produksi oksigen, siklus nutrisi dan penyediaan habitat satwa liar. Pohon penaung menghasilkan serasah yang kemudian menjadi nutrisi bagi tanah melalui proses pembusukan.

- Jasa kultural meliputi rekreasi dan edukasi. Di hutan lindung, sistem agroforestri merupakan sarana edukasi (praktek lapang) dan rekreasi terbatas bagi masyarakat.

2. Pengetahuan masyarakat mengenai layanan ekosistem pada sistem agroforestri yang dikembangkan melalui budi daya kopi di Desa Cisero adalah baik (skor rata-rata 74,86). Masyarakat memiliki pengetahuan sangat baik terkait jasa penyediaan dari sistem tersebut (skor rata-rata 91,46), kemudian diikuti layanan ekosistem dari pohon penaung berupa jasa pengaturan (skor rata-rata 78,66 = baik) dan layanan ekosistem dari keberadaan hidupan liar (skor rata-rata 65,65 = baik). Adapun faktor yang berpengaruh cukup kuat terhadap peningkatan pengetahuan masyarakat antara lain luas lahan garapan, lama interaksi dengan tata guna lahan dan sharing pengetahuan dengan keluarga serta kelompok tani (LMDH).

3. Dalam rangka memelihara layanan ekosistem, beberapa rekomendasi strategi yang dapat diusulkan, antara lain :

a. Penaatan kebijakan kerja sama dan penegakan hukum.

b. Reforestasi dan restorasi terhadap lahan yang rusak.

c. Fasilitasi bantuan modal dan pengaktifan kembali koperasi petani.

d. Peningkatan kapasitas SDM petani secara kontinu.

e. Pendokumentasian dan pengorganisasian data yang baik.

f. Pertanian/perkebunan yang ramah lingkungan. 


\section{DAFTAR PUSTAKA}

Abdoellah OS. 2012. Antropologi ekologi, konsep teori dan aplikasinya dalam konteks pembanguan berkelanjutan. Puslitbang KPK LPPM Universitas Padjadjaran. Bandung.

Arikunto S. 2013. Prosedur penelitian: suatu pendekatan praktik. Rineka Cipta. Jakarta.

Beer J. 1988. Litter production and nutrient cycling in coffee (Coffea arabica) or cacao (Theobroma cacao) plantations with shade trees. Agroforestry Systems 7:103-114.

Budidarsono S dan Wijaya K. 2003. Praktik konservasi dalam budi daya kopi robusta dan keuntungan petani. World Agroforestry Centre - ICRAF South East Asia. Bogor.

Cerdan CR, Rebolledo MC, Soto G, Rapidel B and Sinclair FL. 2012. Local knowledge of impacts of tree cover on ecosystem services in smallholder coffee production systems. Agricultural Systems 110:119-130.

Ginoga K, Lugina M dan Djaenudin D. 2005. Kajian kebijakan pengelolaan hutan lindung. Jurnal Penelitian Sosial \& Ekonomi 2(2):203-231.

Hadiyanti Y. 2014. Evaluasi PHBM dengan sistem agroforestri berbasis kopi melalui pendekatan ecosystem management [Tesis]. Program Studi Magister Ilmu Lingkungan, Universitas Padjadjaran. Bandung.

Iniesta-Arandia I, del Amo DG, Garcia-Nieto AP, Pineiro C, Montes C and MartinLopez B. 2015. Factors influencing local ecological knowledge maintenance in Mediterranean watersheds: insights for environmental policies. AMBIO 44(4):285-296.

Jha KK. 2012. Factors influencing knowledge level of farmers about social forestry. J Hum Ecol 38(3):175-180.

Jose S. 2009. Agroforestry for ecosystem services and environmental benefits: an overview. Agroforestry Systems 76(1):1-10.

Klein AM, Steffan-Dewenter I and Tscharntke T. 2003. Fruit set of highland coffee increases with the diversity of pollinating bees [Proceeding]. Proceedings of the Royal Society of London. Series B: Biological Sciences 270:955-961.

Lynch SJF, Hoelnsteiner RM and Cover CL. 1974. Data Gathering by Social Survei. Philippine Social Science Council. Quezon City.

[MEA] Millennium Ecosystem Assessment. 2005. Ecosystems and human wellbeing: synthesis. Island Press. Washington.

Mendez VE and Bacon CM. 2006. Ecological processes and farmer livelihoods in shaded coffee production. Leisa Magazine 22-23.

Moguel P and Toledo VM. 1999. Biodiversity conservation in traditional coffee systems of Mexico. Conservation Biology 13(1):11-21. 
Mustapit T. 2011. Kontestasi, konflik dan mekanisme akses atas sumber daya agraria (studi kasus reklaiming hutan lindung pada komunitas petani kopi rakyat di Kabupaten Jember). J-SEP 5(1):54-64.

Nansamba R. 2009. Local knowledge about trees and ecosystem services in coffee plantations in Rubavu and Rutsiro Districts, Rwanda [Dissertation]. Bangor University. Wales.

O'Connor T, Rahayu S and van Noordwijk M. 2005. Burung pada agroforestri kopi di Lampung. World Agroforestry Centre. Bogor.

[OECD] Organization for Economic Cooperation and Development. 2003. OECD environmental indicators: development, measurment and use. OECD. Paris.

Perfecto I, Vandermeer J, Mas A and Pinto LS. 2005. Biodiversity, yield, and shade coffee certification. Elsevier. Ecological Economics 54:435-446.

Puspitojati T dan Saefudin I. 2012. Kajian kelembagaan pengelolaan hutan agroforestri bersama dengan masyarakat di kesatuan pemangkuan hutan Bandung Selatan. Seminar Nasional Agroforestri III 375-379.

Ruark GA, Schoeneberger MM and Nair PKR. 2003. Roles for agroforestry in helping to achieve sustainable forest management. UN Forum on Forests (UNFF) Intersessional Experts Meeting. Wellington.

SK (Surat Keputusan) Dewan Pengawas Perhutani Nomor 136/KPTS/DIR/2001 tentang pengelolaan sumberdaya hutan bersama masyarakat.

SK (Surat Keputusan) Direksi Perum Perhutani Nomor 268/KPTS/DIR/2007 tentang pedoman pengelolaan sumberdaya hutan bersama masyarakat plus (PHBM Plus).

Suprapto E. 2014. Policy paper No. 01/2014: kemitraan kehutanan Jawa BaratBanten. Arupa, USAID dan Asian Foundation. Yogyakarta.

Van Noordwijk M, Rahayu S, Hairiah K, Wulan YC, Farida A dan Verbist B. 2002. Carbon stock assessment for a forest-to-coffee conversion landscape in Sumberjaya (Lampung, Indonesia): From allometric equation to land use change analysis. Science in China 45:75- 86. 